\title{
Can Character Solve Our Problems? Character Qualities and the Imagination Age
}

\author{
María García Alvarez \\ Windesheim Honours College and Social Innovation Research Centre, Windesheim University of Applied Sciences, Zwolle, \\ The Netherlands \\ Email: mf.garcia-alvarez@windesheim.nl
}

How to cite this paper: García Alvarez, M (2018). Can Character Solve Our Problems? Character Qualities and the Imagination Age. Creative Education, 9, 152-164. https://doi.org/10.4236/ce.2018.92012

Received: December 10, 2017

Accepted: January 30, 2018

Published: February 2, 2018

Copyright (C) 2018 by author and Scientific Research Publishing Inc. This work is licensed under the Creative Commons Attribution International License (CC BY 4.0).

http://creativecommons.org/licenses/by/4.0/

\begin{abstract}
The emergence of new technology, incorporation of AI to the work floor and rapid pace of change and complexity around us, contribute to the need for a more sophisticated set of skills as key elements for the $21^{\text {st }}$ century and centuries to come. This paper defends the idea that in the Imagination Age we will require more than just the mastery of traditional foundational literacies. Educational institutions should shift the focus towards the training of character qualities. Meta-competencies directly linked with character will provide students with the ability to deal with complex environments. While the importance of character qualities in education is not new, it will become more relevant to prepare the future generations. Educational institutions are urged to rethink their own methods and roles to prepare students to live and collaborate together with new forms of intelligence.
\end{abstract}

\section{Keywords}

Character Qualities, Imagination Age, $21^{\text {st }}$ Century Skills, Complexity, Education

\section{Introduction}

The main goal of education has always been to teach students to understand the world around them. During the Industrialization era, part of the goal as well was to train the future workforce in specific sets of skills and knowledge related to a specific profession. We assisted then to the disassociation of sciences and arts. We separated students by creating standards which organized them by age, capabilities and professional orientation. Students became a product that was able to create economic value by performing labor. Universities became producers of human capital. In the last years, and due to the impact of the dynamics of globa- 
lization, the world today is quite different from the world who welcomed the industrial revolution. The world is becoming more wicked and interconnected, so the traditional approaches to our problems, life, challenges and in particular education, may not work anymore. Educational institutions are engaged in the discussion about how to find effective methods to train students to tackle the wicked problems surrounding us. The term which was originated in the 70s in relation to the complexity of urban planning by Rittel and Weber (1973), is now acquiring relevance linked to global challenges and goals that have even become super wicked problems (Lazarus, 2008; Levin et al., 2012; Metze \& Turnhout, 2014), such is the case of climate change, lack of resources, poverty, etc. These types of problems, as opposed to more "tame" problems, are not just complicated and difficult to solve, but they are unpredictable and unstructured. Wicked problems have multiple, overlapping and interconnected layers of stakeholders' involvement; they have a social, political and cultural transcendence; and they are relentless (Weber \& Khademian, 2008). Other scholars refer to the actual world as a VUCA world (Bennett \& Lemonnie, 2014). VUCA is a term developed by US army after the cold war to define a more volatile, uncertain, complex and ambiguous environment. This term is used today to also describe business and socio-political complexity around the wicked problems. The challenge of this VUCA world is that we are running out of time to find solutions and the lack of central authority needed to address the problems.

This complexity is drawing a new present and future which some define as a transition from the Information Age towards the Imagination Age (King, 2007; Magee, 1993). The Information Age (Castells, 2011) defined the shift from traditional industries towards a more digitalized world thanks to the impact and development of computerization. This resulted in a knowledge economy based societies in which knowledge becomes the value, and digitalization facilitates processes of using information in more effective ways, creating valuable data that can be commercialized. The impact of social media and the miniaturization of devices that allows us to carry technology with us all the time, has transformed normal citizens in prosumers: consumers and producers of data which is transformed in valuable information for private companies and governments (Toffler, 1980). During the Information Age technology is used as a tool to facilitate our work and life. However, the impact of Artificial Intelligence (AI) in the last decade and the speed and exponential growth of robotics, is forcing the shift towards a new form of global society where AI shares working space with humans and helps to shape a new culture and economy based in the implementation of creative ideas. We understand AI as computers and machines (robotics) which "has been given the sophistication needed to act intelligently" (Nilsson, 2014: p. 1) and therefore being able to perform as humans, even sometimes surpassing human capacities (Niewiadomski \& Anderson, 2017). Humans won't be able to compete with AI regarding the process of information and data (Niewiadomski \& Anderson, 2017). The new forms of AI that will develop in the 
near future will help us to solve the complexity of this VUCA world. However, they will also have an impact in the way humans and robotics will work, learn and collaborate together. This means we will have to rethink and redefine the skills that make us human. This fact is leading our transition between the Information Age to the Imagination Age. While the term Imagination Age was first used by Charlie Magee (1993) back in the early 90s, artist and philosopher Rita J. King from the Science House in New York has taken the term to a new level where scientists and artist are starting to work together to prepare our society to thrive in this Imagination Age, as a fundamental step towards the final destination: the Intelligence Age (King, 2007).

If a few years ago the concept of the Imagination Age was mostly popular among futurists, writers and technologists working in the techno-cultural related narratives, more and more educators are starting to explore the consequences of this idea in order to understand the skills that the Imagination Age will require. Rita J. King and his colleague Joshua Fouts, started the project "Imagination: Creating the future of Education and Work" (2010) founded by IBM and the Lounsbery Foundation in order to invite educators to think about this new set of skills and capacities. The results are interesting from the perspective that the set of qualities discussed later in this paper are directed linked to character. Could character related skills be the ones who make us thrive in the new Imagination Age and contribute to a more advance state of our civilization?

In this VUCA world full of wicked problems, where new forms of AI can process and analyze information and knowledge faster and more efficient than us, maybe character qualities are the meta-competences that could help us approach complexity from new perspectives. This paper intends to debate the importance of character qualities as essential skills to deal with the complexity that our actual problems demand and to contribute to a new society where AI and humans collaborate together.

\section{Character Qualities as Overarching Meta-Competences}

What are the skills we need in order to understand and work in this Imagination Age full of challenges, complexities but maybe as well great opportunities? This is a central question for those working in education. When dealing with wicked challenges there is little knowledge structure or rational and logical processes to help solve the problem as for tamed problems (Gosseling \& Tindemans, 2016). While education traditionally mostly focused on competencies in the area of logical problem solving (Ananiadou \& Claro, 2009), an important question is whether these competencies are sufficient to navigate in this new environment where we will share our work and life with AI, taking into consideration that the new forms of AI will be more effective in processing and addressing complex information. The fact is that educational institutions are mostly working with frameworks developed at the end of the $90 \mathrm{~s}$ in the last century. The $21^{\text {st }}$ century skills frameworks were developed to identify literacies, competencies and skills 
that the workforce of the $21^{\text {st }}$ century would need to deal with the complexity the new era requires. Different industry sectors and governments identified different sets of skills that were needed for the Information Age, highly digitalised, but forgot to take into consideration the possibility of a highly robotised world where these new forms of AI will outperform humans regarding process of knowledge and mastery of traditional skills. Most of the frameworks divide skills and competencies in three main sets: foundational literacies (linked to expertise and academically constructed knowledge); skills related to communication and creativity (referring to the capacity of knowledge application); and a third set of competencies linked to the behaviour and attitudes necessary to understand the environment around and interact with others. The latter is often referred to as character qualities. We understand character qualities as a set of meta-competencies that overarch knowledge and traditional skills by being relevant to a wide range of work settings, and by facilitating adaptation and flexibility in collaboration work around complex issues (e.g. Tubbs \& Schulz, 2006; Harden, Crosby, Davis, \& Friedman, 1999). For this paper, I will refer to the $21^{\text {st }}$ century skills framework used by the World Economic Forum since it is used in more than 100 different countries around the world. In the following framework, the character qualities described are: curiosity, initiative, persistence (grit), adaptability, leadership and social and cultural awareness.

This framework, defines each character quality listed as following in relation to the role they can play in education:

- Curiosity: The ability and desire to ask questions and to demonstrate open-mindedness and inquisitiveness.

\section{Exhibit 1: Students require 16 skills for the 21 st century}

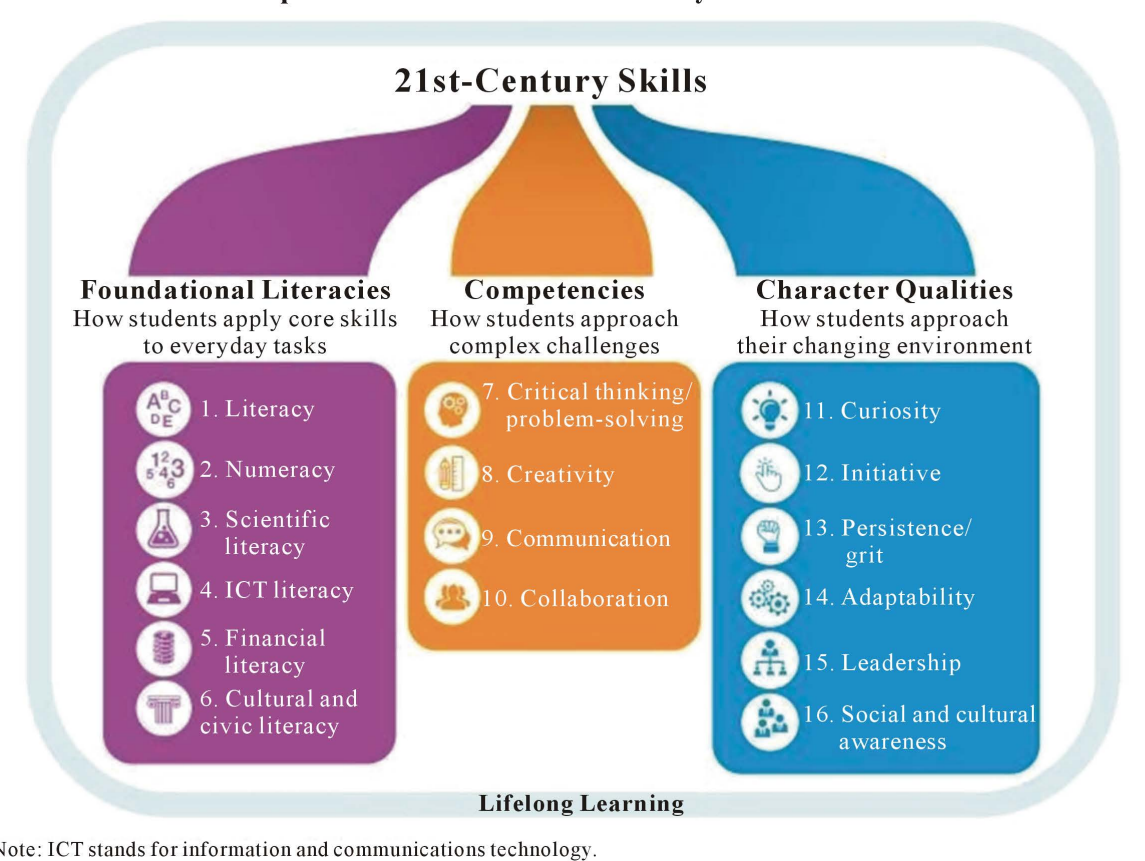

Figure 1. Framework $21^{\text {st }}$ century skills WEF. 
- Initiative: The ability and desire to proactively undertake a new task or goal

- Persistence/grit: Ability to sustain interest and effort and to persevere to accomplish a task or goal.

- Adaptability: Ability to change plans, methods, opinions or goals in light of new information.

- Leadership: Ability to effectively direct, guide and inspire others to accomplish a common goal.

- Social and cultural awareness: Ability to interact with other people in a socially, culturally and ethically appropriate way.

Despite the fact that this last set of meta-competencies are indicated to play an important role in dealing with complexity and understand the world around us by several scholars (e.g. Dede, 2009; Silva, 2009; Voogt \& Roblin, 2012), there is a lack of attention to them in educational settings. This is, at least partly, due to a lack of well-defined assessment policies and explicit and effective ways to train these skills (Ananiadou \& Claro, 2009; World Economic Forum, 2015). A second factor is that most of these meta-competences are related to character, and here the itchy question pops out: can we really train character qualities? While educational institutions brainstorm over this question or simply ignore it, mainly focusing in the foundational literacies we can measure, the industry demands more attention to them and warns that the shift of focus needs to be made. Character qualities development could play an important role in solving the complexity of our problems in this new era as we will discuss further in this paper.

The Business and Industry Advisory Committee to the OECD Survey (BIAC, 2015), carried out among leaders of international leading companies, reveals that in this complex world, employers are increasingly recognizing the importance of character qualities for the workplace. Around $80 \%$ of the surveyed companies considered character qualities would become more important for their organizations in the future. They recommended educational systems to pay more attention to character qualities for the workplace (BIAC, 2015: p. 2). However, as the World Economic Forum report points out, educational systems seem to fail to promote them and train them because of the little consistency in their definition and reliable and valid ways of assessment. Most of the indicators focus on foundational literacies and the development of effective methods for character qualities still remains in an early stage (World Economic Forum, 2015: p. 3). The Center for Curriculum Redesign (CCR), which has clearly defined these so called character qualities after comparison of 32 different $21^{\text {st }}$ Century Skills frameworks, claims in their foundational paper that since the XIX century, "curricula worldwide have often been tweaked, of course, sometimes to a large extent, but have never been deeply redesigned for all relevant dimensions of education: Knowledge, Skills, Character and Meta-Learning" (CCR, 2015: p. 1). These last ones refer to how we behave and engage in the world, while Knowledge and Skills refer to the ability of effectively use what ones knows. From that perspec- 
tive the term character qualities embeds aptitudes, attitudes, behaviors, mindsets, personality and values.

Rita J. King discusses that the education system is still merely link to Industrial Era requirements (exams, classrooms, organisation structure and focus on foundational literacies) (Drew, 2012). Education is not changing fast enough to adjust to the requirements of the business world. Some educators do what they can to prepare their students for the reality of collaborative future with AI and complex issues. However, they are limited by the constrain of curricula mostly constructed around the first pillar of the $21^{\text {st }}$ century skills frameworks. In an interview given to Drew Hansen for Forbes magazine (2012), Rita J. King describes the qualities and skills that we need to thrive in the Imagination Age:

- Balance between individual and the group for meaningful collaboration

- Problem solvers and critical thinkers

- Risk taking

- Curiosity

- Discipline

- Resilience

- Capability to adapt and reinvent yourself

- Capacity to improvise

- Capacity to connect to other cultures

- Future vision: thinking ahead

- Independent learners

As we can see, most of these qualities are linked to the set of character qualities described before. Most recently, the report from McKinsey on What the Future of Work Will Mean for Jobs, Skills and Wages (November 2017) reveals that workers of the future will have to spend more time on the activities that machines and AI are less capable, and therefore the skills and capabilities will require more social and emotional skills and more advanced cognitive capabilities, such as logical reasoning and creativity (McKinsey Global Institute, 2017). Next to this, Stephane Kasriel, CEO of freelancing website Upwork and co-chair of the Council on the Future Work, Gender and Education of the World Economic Forum, defends the idea that the development of AI will not end jobs but create new ones. The work environment won't be defined by a fight humans versus machines, but it will be humans and machines working together. This situation will require a new set of skills from the human capital. In that sense, he points out to the danger not of a shortage of jobs, but a shortage of skills to fit the requirements of those new work environments (Kasriel, 2017).

The $21^{\text {st }}$ Century Skills frameworks and others mentioned in this paper such is the one for the Center for Curriculum Redesign seem to agree in the set of character qualities needed to understand the complexity around us now and what it is to come. Character qualities will contribute to prepare students and young professionals to build a foundation for lifelong learning, support sustainable relations in the community and the workplace, and also develop personal values 
and virtues for sustainable participation in a globalized world shared with other forms of intelligence. In the same line, business leaders and futurists agree as well about the relevance of these set of skills in this new Imagination Age. We seem to have frameworks on place and there is an agreement between educators and workfield about the relevance of these character qualities. Thus, what is holding us back? The following paragraphs discuss the main factors contributing to slow down the process of shifting focus towards character qualities in education: the speed of change and the lack of consistency of terms and definitions and in particular, the debate about if character can be trained or not.

\section{Discussion}

Although the world around us claims a clear shift in the focus of the $21^{\text {st }}$ century skill framework towards meta-competences mostly related to character, educational institutions are not able to keep up the pace of development in the working field. Most of the $21^{\text {st }}$ century skills frameworks were pushed top-down. Educational institutions felt obligated to incorporate them in their existing curricula. However, it took time for this institution to fully adapt the frameworks to their existing programs and by the time they were mostly embedded they became obsolete. These frameworks were developed at the end of the 90s, assisting the demands of computerization and digitalization, but not taking into consideration the exponential growth of robotics and sophisticated forms of AI. Until that moment, keeping up with society to provide and design studies to meet the demand of the work market, was not difficult for education. Growth of technology and impact of new developments in education was giving enough time to predict the skills that should fit the demand of the market (Niewiadomski \& Anderson, 2017). In the last decade, the exponential growth of robotics has taken us all by surprise (the impact of the speed is not limited to the field of education), assisting to new inventions almost every week. Despite the lack of time for adaptation, educational institutions need to rethink the validity of these frameworks and the priority of skills and competences described on them, because as the World Economic Forum predicts, this new age will bring us a change that will affect every aspect of our lives. The landscape of the Imagination Age demands from education to start designing and adapting (and fast) new frameworks that incorporate the collaboration processes with AI. This collaboration and the development of more and more capable forms of AI, will have a profound impact in actual knowledge and skills. Some authors warn us that we cannot remain naïve, and that the exponential growth of AI will create robotics forms of "strong AI" possessing or even exceeding the full range of human cognitive abilities (Niewiadomski \& Anderson, 2017: p. 29).

Another problem that is stopping educational institutions to make a clear shift towards more focus on character qualities is the lack of understanding and agreement around what this set of qualities are. The strict legal frameworks of education (indicators, learning objectives, core mandatory subjects specific to a 
study, etc.) constrain the goal of introducing character qualities in the curriculum. "They specify prioritized learning objectives, they do not offer educators the 'means' by which to achieve those articulated 'ends'” (Chu et al., 2017: p. 18). Character qualities are not a priority. After all they are only in the third column of the most frequently used frameworks.

There is also a lack of consensus in the semantic. Character qualities seems to be a confusing term because of the word "character". Some scholars on character education make a clear link with personality traits, morals, values and emotions (Damon, 2013; De Raad \& Schouwenburg, 1996), and therefore non-cognitive skills, leaving out the possibility of developing training. For the Center for Curriculum Redesign, one of the most important research centers focusing their work on character qualities, there is a clear distinction. To avoid the confusion between personality and character, they decided to refer to this set of meta-competences as "qualities" instead of "traits". When we talk about traits we usually make a direct link to personality and personality traits are usually assumed as fixed and immutable. While personality traits may be indeed fixed and difficult to change, character qualities refer to specific set of mindsets and attitudes. How can attitudes be non-cognitive skills? The attitudes based on complex self-beliefs and beliefs about the complexity of the world imply the use of conscious intellectual judgement and critical thinking, and therefore a conscious intellectual effort and reasoning (Kristjánsson, 2015: p. 5).

If we take a look at the work of the ancient Greek philosophers, they also made that differentiation for character. Aristotle defined character as the combination of two states: the cognitive (knowledge, attitudes and beliefs) and the affective (feelings, desire and emotions), therefore the combination of sentiment and practical reason (Sherman, 1989). This is important because it concludes that character is determined in part by influences from the family, the community and own experience, but building character is a question of practice, and therefore it can be learned. Other Greek philosophers shared this idea of a bi-dimensional character, one related to attitudes and behavior (action) and the other one related to motivation, aims and moral concerns (psychological) (Peterson \& Seligman, 2004).

We can conclude that character qualities can be trained through practice of different activities. Ancient Greek philosophers, and Aristotle in particular, saw the community and the other as a great and fundamental element to develop character. He believes individuals would fully develop their capacities when they work together with group of companions that share the same interest and have common goals. "If we and our cooperative partners do their parts responsibly, each will develop feelings of friendship for the others involved. In this way, successful cooperative activity transforms persons' desires and motivations" (Aristotle, in Rhetoric II.4). He listed examples related to sailors on a ship but also business relationships, citizens and political communities and colleges. Cooperation builds character. This is an interesting point for departure that educational 
environments where students need to collaborate with others, is a perfect setting to help the young professionals develop and build character qualities. Fostering activities that demand from students to work together addressing complexity and interdisciplinary approaches (which demands to think from the perspective of the other) would contribute to the development of character qualities.

In the report of New Vision for Education: Fostering Social and Emotional Learning Through Technology (World Economic Forum, 2016) they propose as well a series of activities that can be used to "teach" or train character qualities (see Figure 2).

Another interesting way of training character qualities is related to vertical learning. It refers to growth of mindset (listed as well in the graphic presented in Figure 2). Activities that contribute to improve our brain plasticity and allow us to adapt our minds to new situations and complexity, and consequently providing us with the capacity to learn, unlearn and relearn (Toffler, 1980). Dutch neuropsychologist Margriet Sitskoorn (2011) defends in her book "Het maakbare brein" that the time where we used to go to college, learn sets of fixed skills linked to a profession, get a diploma and find a job where we applied what we learn in previous years, is over. She thinks that in a VUCA world we cannot

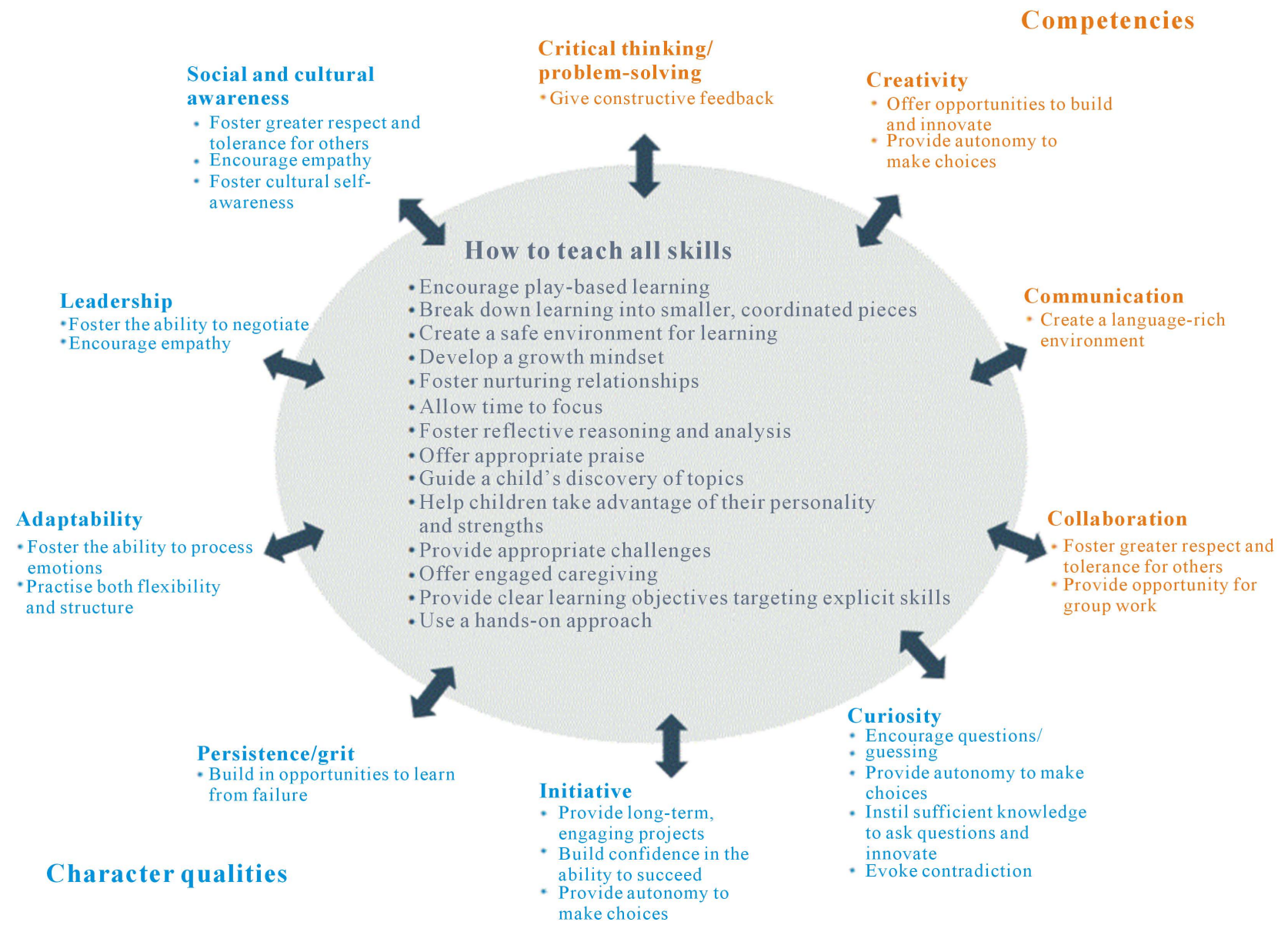

Figure 2. World economic forum, 2016. 
keep living by the same structures and ways of learning that we created during the Industrialization Age. Our society today requires new qualities that shape our brains in order to keep learning and finding the information we need feeding our creativity. Sitskoorn states that training the brain on these new meta competences is not only possible, but essential if we want to survive and keep healthy in this new era full of complexity. From this perspective, students' capacities beyond academic learning of knowledge and skills are more relevant than ever (Camille, 2012). Knowledge and skills, as several reports mentioned in this paper highlight, may be or not be used in future jobs, character qualities will always be applicable not only to a variety of professions but also to the daily life in a new society shared with AI.

The possibility of training students' character should not be questioned but further explore. The Center for Curriculum Redesign, already proposes in its report Character Education for the $21^{\text {st }}$ Century different methods and practices to train students in character qualities and also in how to assess them on their progress. Therefore there are already several solid proposals on how to start training and measuring these qualities. This is a good point of departure and we need to stay open to new ways of training and experiences. In the Imagination Age, shouldn't we have to be more open to imagine and forget the constrains of learning objectives and fixed learning methods? Maybe the key is allowing educators to operate outside of these formal constrains of lectures, schedules, standards and have the same freedom to explore their own creativity. "In this trouble uncertain time, we don't need more command and control; we need better means to engage everyone's intelligence in solving challenges and crisis as they arise" (Wheatly, 1998: p. 40).

We need a shift in the discussion about if character qualities can be trained or not towards more focus in researching the possibilities and effects of existing frameworks and experiences. Only then we may be able to adapt to the exponential growth of technology and its consequents changes in society and in our economy. The most recent and complete report evaluating the implementation and measurement of 21st skills frameworks among 100 countries (World Economic Forum, 2015) suggests the need for development of effective and clear indicators measuring character qualities. Further research and experimentation is clearly needed about this topic.

\section{Conclusion}

There is an urge to start rethinking educational settings and curricula. Research concludes that meta-competence should be part of the university curricula (Klaus, 2010; Robles, 2012) and also play a key role in educational settings where students are increasingly required to work in teams solving complex problems and questions (Feltovich et al., 1996; Gibb, 2002; Sears \& Reagin, 2013; Brandler \& Roman, 2015). The world is changing fast and we will need to share space with new forms of intelligence that can process and select information in much more 
effective ways that our human brains do. We need to be able to meet the demands of the work field claiming for a shift towards other sets of more creative and critical thinking skills and meta-competences that are more related to values, attitudes and character.

As the World Economic Forum proposes in the report "New Vision for Education" (WEF, 2015: p. 5), combination of character qualities can be the key to thrive in this Imagination Age and deal with the wickedness around us:

- Persistence and adaptability ensure greater resilience and success in the face of obstacles.

- Curiosity and Initiative serve as starting points for discovering new concepts and ideas.

- Leadership and social and cultural awareness involve constructive interactions with others in socially, ethically and culturally appropriate ways.

Educational institutions will need to develop creative and challenging environments for lectures and students to explore new ways of effective training. We need to facilitate the growth of new capacities that allows them to recognise multiple knowledge cultures, strategic understanding of a complex world and to be able to adapt to uncertainty. We all need not only to accept the inevitable: AI will reshape the job market and our economies. This is a challenge, and also a great opportunity for new forms of learning, embracing a new era where humans can focus in developing their character and exploring their creativity. Character will allow us to accept all the different views in the world and acknowledge our responsibilities in new forms of societies. The Ancient Greek understood that you cannot separate sciences from arts; they both speak a common language. The educational model resulted from the Industrialization Age made the mistake to separate them, and the Imagination Age may be able to integrate them together again. Character qualities as well as other skills related to creativity have been usually isolated to the fields of the Arts, Technology and robotics to Science. Let's create collaborative spaces in the university where sciences and arts grow together. The Imagination Age is here. Let's start imagining.

\section{References}

Ananiadou, K., \& Claro, M. (2009). 21st Century Skills and Competences for New Millennium Learners in OECD Countries. OECD Education Working Papers, No. 41. Paris: OECD Publishing.

Bennett, N., \& Lemoine, G. J. (2014). What a Difference a Word Makes: Understanding Threats to Performance in a VUCA World. Business Horizons, 57, 311-317.

BIAC (2015). Character Qualities for the Workplace: BIAC Survey. Paris. http://biac.org/wp-content/uploads/2015/06/15-06-Synthesis-BIAC-Character-Survey1 .pdf

Brandler, S., \& Roman, C. P. (2015). Group Work: Skills and Strategies for Effective Interventions. UK: Routledge.

Camille, A. (2012). Teaching Adolescents to Become Leaders: The Role of Noncognitive Factors in Shaping School Performance. A Critical Literature Review, Consortium of Chicago School Research. 
Castells, M. (2011). The Rise of the Network Society: The Information Age: Economy, Society, and Culture (Vol. 1). New York: John Wiley \& Sons.

CCR (2015) Center for Curriculum Redesign Report on Character Qualities. http://curriculumredesign.org/wp-content/uploads/CCR-CharacterEducation_FINAL_ 27Feb2015.pdf

Chu, S. K. W., Reynolds, R. B., Tavares, N. J., Notari, M., \& Lee, C. W. Y. (2017). Twenty-First Century Skills and Global Education Roadmaps. In 21st Century Skills Development through Inquiry-Based Learning (pp. 17-32). Singapore: Springer. https://doi.org/10.1007/978-981-10-2481-8_2

Damon, W. (2013). Bringing in a New Era in Character Education (No. 508). Hoover Press.

Dede, C. (2009). Immersive Interfaces for Engagement and Learning. Science, 323, 66-69.

De Raad, B., \& Schouwenburg, H. C. (1996). Personality in Learning and Education: A Review. European Journal of personality, 10, 303-336. https://doi.org/10.1002/(SICI)1099-0984(199612)10:5<303::AID-PER262>3.0.CO;2-2

Drew, H. (2012). Imagination: What You Need to Thrive in the Future Economy. Forbes Magazine (Opinion, April).

https://www.forbes.com/sites/drewhansen/2012/08/06/imagination-future-economy/\#5 e785ec656dc

Feltovich, P. I., Coulson, R. L., \& Peltovich, J. (1996). Complexity, Indivitually and in Groups. CSCL, Theory and Practice of an Emerging Paradigm, 25.

Gibb, A. (2002). Creating Conductive Environments for Learning and Entrepreneurship. Living with, Dealing with, Creating and Enjoying Uncertainty and Complexity (pp. 135-147). Industry and Higher Education.

https://doi.org/10.5367/000000002101296234

Gosselin, D., \& Tindemans, B. (2016). Thinking Futures: Strategy at the Edge of Complexity and Uncertainty. Lannoo Meulenhoff-Belgium.

Harden, J. R., Crosby, M. H., Davis, M., \& Friedman, R. M. (1999). AMEE Guide No. 14: Outcome-Based Education: Part 5-From Competency to Meta-Competency: A Model for the Specification of Learning Outcomes. Medical Teacher, 21, 546-552.

https://doi.org/10.1080/01421599978951

Hansen, D. (2012). What You Need to Thrive in the Future Economy. Interview to Rita J. King 6 December 2012, Forbes Magazine.

https://www.forbes.com/sites/drewhansen/2012/08/06/imagination-future-economy/\#5 d433a3c56dc

King, R. J. (2007). The Emergence of a New Global Culture in the Imagination Age. Published in British Council Essays.

http://archive.is/20120722122948/www.britishcouncil.org/tn2020-research-findings-au thors-king.htm

Kasriel, S. (2017). 4 Predictions for the Future of Work. Blog Post. https://www.weforum.org/agenda/2017/12/predictions-for-freelance-work-education

Klaus, P. (2010). Communication Breakdown. California Job Journal, 28, 1-9.

Kristjánson, K. (2015). Aristotelian Character Education. Abingdon-on-Thames: Routledge.

Lazarus, R. J. (2008). Super Wicked Problems and Climate Change: Restraining the Present to Liberate the Future. Cornell Law Review, 94, 1153.

Levin, K., Cashore, B., Bernstein, S., \& Auld, G. (2012). Overcoming the Tragedy of Super Wicked Problems: Constraining Our Future Selves to Ameliorate Global Climate Change. Policy Sciences, 45, 123-152. https://doi.org/10.1007/s11077-012-9151-0 
Magee, C. (1993) The Age of Imagination: Coming Soon to a Civilization Near You. In Second International Symposium: National Security \& National Competitiveness: Open Source Solutions (Vol. 1). Washington DC: Shoreham http://www.oss.net/dynamaster/file_archive/040320/4a32a59dcdc168eced6517b5e6041 cda/OSS1993-01-21.pdf

Metze, T., \& Turnhout, E. (2014). Politiek, Participatie en experts in de besluitvorming over super wicked problems. Bestuurskunde, 23, 1-48. https://doi.org/10.5553/Bk/092733872014023002001

MCKinsey Global Institute (2017). Special Report on Future of Organizations and Work: What the Future of Work Will Mean for Jobs, Skills and Wages. https://www.mckinsey.com/global-themes/future-of-organizations-and-work/what-the -future-of-work-will-mean-for-jobs-skills-and-wages

Niewiadomski, R., \& Anderson, D. (2017). The Rise of Artificial Intelligence: Its Impact on Labor Market and Beyond. In Strategic Imperatives and Core Competencies in the Era of Robotics and Artificial Intelligence (pp. 29-49). IGI Global.

Nilsson, N. J. (2014). Principles of Artificial Intelligence. Morgan Kaufmann. https://stacks.stanford.edu/file/druid:zd294jv9941/zd294jv9941.pdf

Peterson, C., \& Seligman, M. E. (2004). Character Strengths and Virtues: A Handbook and Classification (Vol. 1). Oxford: Oxford University Press.

Rittel, H. W., \& Webber, M. M. (1973). 2.3 Planning Problems Are Wicked. Polity, 4, 155-169.

Robles, M. (2012). Executive Perceptions of the Top 10 Soft Skills Needed in Today's Workplace. Business Communication Quarterly, 75, 453-465. https://doi.org/10.1177/1080569912460400

Sears, D. A., \& Reagin, J. M. (2013). Individual versus Collaborative Problem Solving: Divergent Outcomes Depending on Task Complexity. Instructional Science, 41, 1153-1172. https://doi.org/10.1007/s11251-013-9271-8

Sherman, N. (1989). The Fabric of Character: Aristotle's Theory of Virtue.

Sitskoorn, M. (2011). Het Maakbare Brein. Prometheus.

Silva, E. (2009). Measuring Skills for 21st Century Learning. The Phi Delta Kappan, 90, 630-634. https://doi.org/10.1177/003172170909000905

Tubbs, S. L., \& Schulz, E. (2006). Exploring a Taxonomy of Global Leadership Competencies and Meta-Competencies. Journal of American Academy of Business, 8, 29-34.

Toffler, A. (1980). The Third Wave: The Classic Study of Tomorrow. New York, NY: Bantam.

Voogt, J., \& Roblin, N. P. (2012). A Comparative Analysis of International Frameworks for 21st Century Competences: Implications for National Curriculum Policies. Journal of Curriculum Studies, 44, 299-321. https://doi.org/10.1080/00220272.2012.668938

Weber, E. P., \& Khademian, A. M. (2008). Wicked Problems, Knowledge Challenges, and Collaborative Capacity Builders in Network Settings. Public Administration Review, 68, 334-349. https://doi.org/10.1111/j.1540-6210.2007.00866.x

Wheatley, M. J., \& Rogers, M. E. (1998). A Simpler Way. Oakland, CA: Berrett-Koehler Publishers.

World Economic Forum (2015). New Vision for Education Report: Unlocking the Potential of Technology. Geneva.

http://www3.weforum.org/docs/WEFUSA_NewVisionforEducation_Report2015.pdf

World Economic Forum (2016). New Vision for Education: Fostering Social and Emotional Learning through Technology. Geneva.

http://www3.weforum.org/docs/WEF_New_Vision_for_Education.pdf 